\title{
A PROMOÇÃO DOS DIREITOS HUMANOS EM UMA INSTITUIÇÃO DE ENSINO SUPERIOR: RELATO DE EXPERIÊNCIA DO PROJETO DIVERSIDADE
}

\author{
Jéferson Luis Staudt \\ Universidade Feevale \\ jefersonstaudt@yahoo.com.br
}

André Luiz dos Santos Silva Universidade Feevale andrels@feevale.br

\section{Resumo}

Esse texto apresenta e avalia as intervenções do Projeto Diversidade que foi desenvolvido pela Secretaria de Direitos Humanos do Diretório Central dos Estudantes de uma Instituição de Ensino Superior localizada no município de Novo Hamburgo-RS. Tendo como eixo metodológico as teorizações advindas dos Estudos Culturais, esse projeto objetivou representar e acolher identidades étnico-raciais, de gênero e de orientação sexual com fins a promoção dos direitos humanos e da cidadania na e pela Instituição. Para tanto, o Projeto Diversidade desenvolveu atividades como forma de representação dessas minorias sociais. Enquanto proposta política e social o Projeto Diversidade oportunizou espaços privilegiados de discussão política sobre racismo, machismo e homofobia, fomentando a positivação de identidades étnicas e de gênero, bem como oferecendo subsídios teóricos e práticos para que licenciandos/as pudessem promover práticas pedagógicas com vistas à promoção da igualdade social, da cidadania e dos direitos humanos em outras instituições de ensino.

Palavras-chave: Direitos Humanos. Cidadania. Diversidade. Representação.

\section{PROMOTING HUMAN RIGHTS IN AN INSTITUTION OF HIGHER EDUCATION: PROJECT EXPERIENCE REPORT DIVERSITY}

\begin{abstract}
This paper presents the operations of the Diversity Project which was developed by the Human Rights Secretariat of the Central Directory of a higher education institution students in the municipality of Novo Hamburgo-RS. The methodological axis theorizations arising from cultural studies, this project aimed to represent and accept ethnic and racial identity, gender and sexual orientation purposes with the promotion of human rights and citizenship on and by the institution. Therefore, the Diversity Project had developed activities as a form of representation of these political minorities. As proposed political and social; the Diversity Project provided an opportunity privileged spaces for political discussion on racism, sexism and homophobia, encouraging positivization ethnic and gender identities, as an educational proposal; it offered theoretical and practical subsidies for the promotion of educational practices with the purpose of promoting social equality, citizenship and human rights.
\end{abstract}

Keywords: Human Rights. Citizenship. Diversity. Representation.

\section{PROMOCIÓN DE LOS DERECHOS HUMANOS EN UN INSTITUCIÓN DE EDUCACIÓN SUPERIOR: INFORME DE EXPERIENCIA}

\footnotetext{
Resumen

Este artículo evalúa las operaciones del Proyecto de Diversidad que fue desarrollado por la Secretaría de Derechos Humanos del Directorio Central de Estudiantes de una institución de educación superior en la ciudad de Novo HamburgoRS. los ejes metodológicos son derivados de los estudios culturales e este proyecto tenía como objetivo representar y aceptar la identidad étnica y racial, de género y de forma orientativa sexuales con la promoción de los derechos humanos y ciudadanos, así como por la institución. Por lo tanto, el Proyecto de Diversidad ha desarrollado actividades como una forma de representación de estas minorías políticas. Como propuesta política y social; el Proyecto de Diversidad proporciona espacios privilegiados una oportunidad para la discusión política sobre el racismo, el sexismo y la homofobia como una propuesta educativa; Se ofreció subsidios teóricos y prácticos para la promoción de las prácticas educativas con el fin de promover la igualdad social, la ciudadanía y los derechos humanos.

Palavras clave: Derechos Humanos. La ciudadanía. Diversidad. Representación.
} 
A promoção dos direitos humanos em uma instituição de ensino superior: relato de experiência do Projeto Diversidade

\section{INTRODUÇÃO}

A Declaração Universal dos Direitos Humanos (1948) vem suscitando distintos questionamentos desde a sua proclamação. Dentre eles, a própria ideia de direitos humanos universais vem sendo tensionada. No cerne dessa questão está à relação entre o universal e o particular. Nesse sentido, diversos grupos estão interrogando a universalidade dos direitos humanos, sobretudo, por se tratar de uma medida de proteção e promoção da dignidade humana construída a partir de uma perspectiva ocidental europeia (CANDAU, 2008).

A Declaração dos Direitos Humanos expressa por meio de direitos universais a todos/as tem sido concebida como uma forma insuficiente de representar determinadas individualidades/coletividades que possuem demandas singulares e, que por essa razão, necessitam de medidas públicas mais específicas, caso das seguintes minorias sociais: mulheres, negros/as, gays, lésbicas e pessoas trans. Por essa razão, se percebe que a diferença tem sido tomada como ferramenta para a promoção dos direitos humanos de grupos em situação de vulnerabilidade social (PIOVESAN, 2005).

De fato, o discurso de igualdade entre os seres humanos esteve no centro da luta por direitos humanos. No entanto, o enfoque tem repousado predominantemente sobre a diferença, ou melhor, sobre a relação entre a igualdade e a diferença. Esse deslocamento tem ampliado a noção de Direitos Humanos enquanto direitos civis e políticos para incluir questões como direitos individuais, valorização social e representação política e cultural (CANDAU, 2008).

O desvio de foco da igualdade para a diferença apoia-se nas múltiplas formas de exclusão social, discriminação, injustiças e desigualdades que são produzidas a partir das diferenças étnicoraciais, de gênero e de orientação sexual no contexto cultural. Essas são apenas algumas das problemáticas que os movimentos sociais vêm descortinando por intermédio de reivindicações políticas em busca de reconhecimento, valorização e igualdade de acesso a bens e serviços (CANDAU, 2008).

Desse modo, as minorias sociais reivindicam não apenas o direito dos diferentes serem iguais, mas, fundamentalmente, o direito à diferença, ou seja, de poder viver e experimentar a sua diferença dentro das suas diversas especificidades e possibilidades. Nessa direção, uma proposta que vise a promoção dos Direitos Humanos implicaria em ressignificar sua definição e articular a concepção de igualdade e diferença a partir de uma perspectiva cultural (PIOVESAN, 2005; CANDAU, 2012). 
A promoção dos direitos humanos em uma instituição de ensino superior: relato de experiência do Projeto Diversidade

Os nexos entre o cultural e o social se engendram nos domínios da prática e da significação e atestam que toda prática social é também prática de significação. Os significados que conferimos às práticas são extraídos de uma rede de sentidos que as pessoas utilizam para codificar e organizar as relações sociais, permitindo aos sujeitos interpretar de forma significativa as ações dos/as outros/as. Concebido em seu conjunto, tais códigos de significação constituem a nossa cultura (HALL, 1997).

Por assim dizer, a cultura passou a ser entendida como elemento constituinte da vida social e empregada como conceito explicativo e analítico de particular importância, na medida em que modela e regula as nossas condutas e práticas sociais e, desse modo, as formas como nos relacionamos na sociedade. Por essa razão, percebe-se que os conflitos por poder são cada vez mais simbólicos e discursivos ao invés de serem meramente físicos ou concretos. Isso torna a cultura um dos elementos mais dinâmicos e imprescindíveis da atualidade. Pensemos: Se a cultura regula as condutas sociais, dentre as quais, os processos de exclusão por diferenças étnico-raciais, de gênero e orientação sexual, então quer dizer que determinados grupos que pretendem manter essas relações desiguais precisariam, em alguma medida, controlar os processos de representação cultural para moldá-las, regulá-las e mantê-las (HALL, 1997).

Quando falamos em representação, estamos nos referindo a um sistema cultural de particular importância para se pensar as maneiras como se sustentam e se perpetuam relações sociais assimétricas, por se tratar de um dos principais mecanismos de produção de cultura. $\mathrm{Na}$ prática, a representação produz sentidos sobre o "O outro" e produz identidades culturais que tem seus sentidos manifestos nas formas como as relações sociais se organizam (WORTMANN, 2001; SILVA, 2014; WOODWARD, 2014).

A representação também e, sobretudo, está diretamente ligada a relações de poder. Em outras palavras, os grupos hegemônicos ao deter os processos de representação dos demais grupos, possui o privilégio de atribuir-lhes os valores que desejar e assim, de produzir práticas sociais que descriminam esse/a outro/a cultural. Nesse caso, ao dispor dos processos de representação, controla, define e marca as identidades étnicas, de gênero e sexuais desejáveis e "normais" e ainda, produz e reproduz estigmas, estereótipos, preconceitos e discriminações (HALL, 1997; SILVA, 2014).

Nesse sentido, este artigo narra o percurso acadêmico do Projeto Diversidade, proposto pela Secretaria de Direitos Humanos do Diretório Central dos Estudantes em uma Instituição de Ensino Superior de Novo Hamburgo-RS. Esse projeto foi encaminhado à Instituição como 
A promoção dos direitos humanos em uma instituição de ensino superior: relato de experiência do Projeto Diversidade

proposta de intervenção interdisciplinar que vislumbrava tensionar questões como relações étnico-raciais, relações de gênero e diversidade sexual.

As atividades propostas pelo projeto foram registradas em diário de campo e tiveram como eixo teórico e metodológico as proposições dos Estudos Culturais. De forma específica, o conceito de representação (WORTMANN, 2001; SILVA, 2014; WOODWARD, 2014) norteou a proposta e as atividades desenvolvidas nos anos de intervenção do projeto na Universidade. O Projeto Diversidade pretendeu promover momentos de questionamento e desconstrução de representações culturais que vem sendo construídas ao longo dos tempos e que produzem sentidos pejorativos sobre mulheres, negros/as e homossexuais, representações que contribuem para a manutenção de uma cultura de preconceito, discriminação e violência à diversidade social e cultural.

Nesse sentido, este texto se organiza do seguinte modo: primeiro é apresentada a proposta que foi encaminhada a Instituição, em seguida são apresentadas e avaliadas as atividades desenvolvidas pelo projeto e por fim, são tecidas algumas considerações finais.

\section{PROJETO DIVERSIDADE: A PROPOSTA, A PROBLEMÁTICA E SUA JUSTICATIVA}

\section{PROBLEMA}

O Projeto Diversidade foi pensado por e para as minorias sociais, a fim de dar voz e visibilidade aos grupos socialmente discriminados e negligenciados. A intenção foi construir em articulação com a Universidade, um espaço no qual as minorias sociais se vissem e se reconhecessem representadas; um lugar acadêmico e político, onde seus anseios, desejos e pensamentos pudessem ser ouvidos e, efetivamente, considerados, contestando as relações de poder pelas quais essas vozes têm sido silenciadas.

Historicamente desfavorecidas, perseguidas e discriminadas, as minorias sociais são marginalizadas devido a sua posição social não hegemônica. Contudo, desejam e precisam dar vOz e novos significados às suas matrizes culturais, suas crenças, suas religiões, seus valores morais e ainda, a todas as suas maneiras de sentir, pensar, agir e viver em sociedade (PIOVESAN, 2005; CANDAU, 2012).

Todavia, a cultura que possui prestígio social é justamente a cultura dos grupos hegemônicos: seus valores, comportamentos e modos de agir. Temos então, a cultura como um 
A promoção dos direitos humanos em uma instituição de ensino superior: relato de experiência do Projeto Diversidade

campo de luta e disputa por valores, signos e propósitos sociais, um campo de imposições e resistências (SILVA, 2011).

$\mathrm{Na}$ medida em que uma determinada cultura tem valor social e outras não, no momento em que essa cultura vale alguma coisa e as pessoas que a possuem obtenham vantagens materiais e simbólicas sobre outras pessoas, a cultura se reverbera um capital. Porém, no instante em que a cultura, a estética e o comportamento dos grupos não hegemônicos são representados de forma pejorativa pelos grupos hegemônicos por meio de aparatos discursivos e institucionais, essas práticas se materializam em exercícios de poder, que nesse caso, simbolizam o poder de representar o/a outro/a cultural e conferir-lhe sentidos de forma verticalizada e arbitrária (SILVA, 2011; SILVA, 2014).

É sabido que padrões humanos são compartilhados socialmente, todavia, tais padrões balizam e circunscrevem a óptica, o pensar em relação aos corpos, deixando margem para o surgimento de preconceitos e causando estranheza por não compartilharem dos mesmos modelos humanos. Pensar em corpos é pensar em diferenças. No entanto, são justamente essas diferenças que alicerçam e movem os atos de violência física e psicológica sofridos pelas minorias sociais.

As questões que foram contextualizadas e potencializadas na referida proposta, foram construídas historicamente no convívio social. Essa convivência apontou para a presença de demandas que potencializavam discussões e ações no âmbito acadêmico.

Neste sentido, considerando a missão da referida Instituição de ensino de produzir conhecimento, democratizar o saber e a formação dos indivíduos, a proposta de intervenções questionou: que sujeitos se quer formar?

A proposta deixou claro que a intenção não era desconstruir o currículo acadêmico, mas sim, acenar para a necessidade de potencializar o que às vezes está oculto no currículo que perpassa a formação dos/as acadêmicos/as dessa Instituição de ensino.

Visto isso, a proposta enfatizou a necessidade de inserir os/as acadêmicos/as no debate sobre minorias sociais, para que pudessem tomar consciência de uma realidade produzida e reproduzida nas relações sociais, inclusive, na Instituição. Incentivar os questionamentos acerca das representações negativas que perpetuam as desigualdades entre heterossexuais e homossexuais; desconstruir os aparatos discursivos e linguísticos que impingem marcas pejorativas em pessoas negras e evidenciar as forças que permitem imposições de forma arbitrária frente às mulheres. 
A promoção dos direitos humanos em uma instituição de ensino superior: relato de experiência do Projeto Diversidade

Partindo ainda da premissa proposta pela Universidade de consideração à diversidade social, cultural e étnica, cooperando assim, para acessão da equidade social, a presente proposta vislumbrou o apoio da Universidade a uma política inovadora, contribuindo para que a Instituição se consolide como um ambiente de referência em direitos humanos e cidadania.

\section{JUSTIFICATIVA}

As corriqueiras buscas pelo "outro" costumeiramente movidas por datas comemorativas, fazem alusão muito superficial às culturas não hegemônicas. Diante disso, se faz necessário pensar em abordagem mais abrangente, corriqueira e transversal sobre as temáticas relações étnico-raciais, relações de gênero e sexualidade.

Estamos na iminência da chamada Década Internacional de Afrodescendentes, aprovada pela Assembleia Geral da ONU, no dia 23 de Dezembro de 2013. Com a temática "Afrodescendentes: reconhecimento, justiça e desenvolvimento", o decênio é celebrado de $1^{\circ}$ de Janeiro de 2015 a 31 de Dezembro de 2024.

A mencionada década oportuniza eventos de conscientização sobre a necessidade de combater a violência, a descriminação e o preconceito, ainda presentes entre os povos em razão do racismo. A década ilustra e evidencia que o racismo perpassa a história dos povos e que precisa ser pauta de ações e políticas voltadas para as relações étnico-raciais, sobretudo, no Brasil, que possui a maior população de ascendência africana fora do continente (BRASIL, 2013).

Nessa direção é importante mencionarmos o Conselho Nacional de Educação, que na Resolução CNE/CP no 1, de 17 de junho de 2004 (BRASIL, 2004), instituiu diretrizes curriculares nacionais para a Educação das Relações Étnico-raciais e para o ensino da História e da Cultura Afro-brasileira e Africana, a serem observadas pelas instituições em todos os níveis de ensino, em especial, por instituições que desenvolvem programas de formação inicial e continuada de professores.

A resolução tem por base o parecer do CNE/CP nº 3, de 10 de março de 2004, homologado pelo Ministro da Educação, em 19 de maio de 2004. As decisões do Conselho Nacional de Educação cumprem a Lei no 10.639, de 9 de Janeiro de 2003 (BRASIL, 2003), que alterou a Lei $\mathrm{n}^{\circ}$ 9.394, de 20 de dezembro de 1996 (LDB), para tornar obrigatório o ensino da História e da Cultura Afro-Brasileira na Educação Básica.

Todos esses dispositivos legais convergem para a inclusão do estudo da História da África e dos Africanos, da luta dos/as negros/as no Brasil, da cultura Afro-brasileira e da importância 
A promoção dos direitos humanos em uma instituição de ensino superior: relato de experiência do Projeto Diversidade

do/a negro/a na formação da sociedade nacional, resgatando a contribuição do povo negro nas áreas social, econômica e política pertinente à História do Brasil.

Todavia, a temática não é abordada de maneira abrangente e incisiva, o que aponta para a necessidade de políticas empenhadas no reconhecimento e na valorização da Historia e da cultura dos/as afro-brasileiros/as, promovendo uma relação étnico-social positiva e desse modo, fomentando a cidadania.

A promulgação da Lei $\mathrm{n}^{\circ}$ 10.639, de 9 de Janeiro de 2003, atende ainda a demanda da comunidade afro-brasileira por reconhecimento, valorização e afirmação de direitos no que diz respeito à educação e favorece a identificação do/a negro/a às suas raízes africanas.

Essa proposta de intervenções atende, inclusive, ao que foi determinado pelo Programa Nacional de Direitos Humanos, bem como aos compromissos internacionais assumidos pelo Brasil, com o objetivo de combate ao racismo e às discriminações, dentre os quais: a Convenção da UNESCO (1960), voltada ao combate do racismo em todas as formas de ensino, bem como a Conferência Mundial de Combate ao Racismo, Discriminação Racial, Xenofobia e Discriminações Correlatas (2001) (GOES; SILVA, 2013).

Dessa forma, concebe-se que ações políticas e culturais voltadas para os segmentos afrodescendentes da sociedade brasileira seriam formas de representação positiva do/a negro/a na Instituição, representações com as quais os sujeitos negros/as possam se identificar e estreitar o distanciamento existente com as instituições de ensino superior. São nesses pressupostos que residem algumas das intenções deste projeto, ao fomentar um lócus para o debate e visibilidade sobre/das representações negras na Universidade.

Ainda sobre as minorias sociais, é importante apontar a necessidade de discutir e potencializar, inclusive, as temáticas relações de gênero e sexualidade nessa universidade. Essa assertiva parte do entendimento de que a educação configura-se com uma estratégia capaz de favorecer a diversidade e a aceitação das diferenças, que poderá ainda, em curto prazo, promover o enfrentamento do preconceito, da discriminação e de qualquer ato violento relacionado com as questões de gênero e sexualidade (BRASIL, 2007).

Problemas emergentes de (pre)conceitos relacionados, sobretudo, às identidades de gênero e orientação sexual, não raras vezes, culminam em violência e, em alguns casos, morte. Assim, é preciso a adoção de políticas que discutam e problematizem sobre tais temáticas de forma a enfrentar a óptica discriminatória e machista arraigada historicamente na sociedade.

Dentre os "Princípios Orientadores" da Instituição de ensino, especificamente aqueles que versam sobre "Diversidade", é possível identificar o compromisso dessa Instituição com a 
A promoção dos direitos humanos em uma instituição de ensino superior: relato de experiência do Projeto Diversidade

heterogeneidade social, cultural e étnica, bem como com a promoção da equidade social e com a valorização da diversidade na educação. Dessa maneira, devido à ausência de ativas políticas educacionais de combate ao preconceito, a referida proposta parte dessas premissas e compreende o espaço institucional como ambiente capaz de acolher identidades e dar voz e reconhecimento às diferentes formas de viver e se relacionar em sociedade ${ }^{1}$.

A construção de sujeitos humanos dotados de corpos e perpassados por sexos, sexualidades e identidades de gênero diferentes, implica em observarmos e problematizarmos as relações sociais que se estabelecem em meio às diversidades corpóreas e de relações afetivosociais.

Pode-se dizer que em âmbito nacional foi a Constituição de 1988, o marco institucionallegal mais relevante no que tange aos direitos humanos (BRASIL, 1988). Contudo, as discussões em torno das metas e da formulação de políticas destinadas às mulheres e à população LGBT ${ }^{2}$ foram aprimoradas e resultaram no lançamento do Programa Brasil sem Homofobia (BSH) e do Plano Nacional de Políticas para as Mulheres (PNPM), este, revisado na gestão da Presidenta Dilma Rousseff (BRASIL, 2004; 2013).

O PNPM e o BSH configuram um conjunto de compromissos e planos de ação do Governo Federal para a formulação e implementação de políticas integradas e de caráter nacional, voltadas, sobretudo, para enfrentar as desigualdades e sensibilizar e capacitar gestores/as públicos/as para o combate ao preconceito, à discriminação e a violência contra mulheres e à LGBT’s, nas áreas da educação, da cultura, da saúde, do trabalho, da segurança etc.

Todos os dispositivos legais supracitados convergem na intencionalidade da referida proposta em transformar a Instituição em um espaço de desconstrução de visões conservadoras e de questionamento de lógicas hegemônicas reprodutoras de opressão, promovendo uma cultura de respeito, reconhecimento e valorização da diversidade, dos direitos humanos e da cidadania.

Infere-se que preconceitos e estereótipos de gênero e sexualidade são passíveis de desconstrução diante de políticas educacionais emancipatórias. As intervenções dessa proposta possibilitam refletir criticamente e questionar sobre relações de poder, hierarquizações e sobre usos "adequados" dos corpos.

Sendo assim, se torna essencial erigir uma política que vise implementar uma educação não-sexista e superadora da homofobia; que evidencie as vantagens materiais e simbólicas que os homens possuem sobre as mulheres; que incite a valorização às iniciativas culturais das mulheres;

1 Tais "Princípios Orientadores" são expressos nos guias acadêmicos que a Universidade disponibiliza para a retirada dos/as acadêmicos/as no inicio de cada semestre.

2 LGBT compreende lésbicas, gays, bissexuais, travestis, transexuais e transgêneros. 
A promoção dos direitos humanos em uma instituição de ensino superior: relato de experiência do Projeto Diversidade

que favoreça a não violência contra mulheres e homossexuais; que respeite os direitos afetivosexuais; que desconstrua visões discriminatórias e estereotipadas e que estimule a pesquisa e a difusão de conhecimentos que contribuam para o combate a violência contra mulheres e a discriminação LGBT.

\section{DURAÇÃO DO PROJETO}

Dois anos (de 2014 a 2015).

\section{OBJETIVOS DO PROJETO}

O Projeto Diversidade tem como finalidade tematizar, problematizar e sensibilizar acerca de problemas que atingem identidades e coletividades socialmente desfavorecidas, a fim de proporcionar aos/as acadêmicos/as da Universidade uma visão mais crítica e humanista.

Além disto, este projeto visa tencionar as representações pejorativas das coletividades, que desempenham o papel de estigmatizar os corpos, perpetuando os preconceitos.

Nesse sentido, o pretende acolher identidades e dar voz e visibilidade às minorias sociais, proporcionando o sentimento de pertencimento à Instituição diante da impressão de se verem como parte reconhecida e valorizada na e pela Universidade.

\section{ATIVIDADES QUE FORAM PROPOSTAS}

* Oficinas de cultura: Oficinas ministradas na Universidade com as seguintes temáticas: lutas e danças que contemplaram manifestações da "Cultura Afro-brasileira. Atividades abertas à comunidade acadêmica, além dos/as alunos/as da Instituição que desejem fazer parte das práticas.

* Grupo de discussão: Composto por acadêmicos/as empenhados/as em leituras e debates que contemplem as temáticas do Projeto. O grupo de discussão teve a intenção de ser uma linha de formação acadêmica e pretendia ainda, estabelecer aproximações com grupos de pesquisa, projetos de extensão e linhas de formação da Instituição que investigassem as temáticas que atendessem aos objetivos da pela proposta.

*Eventos: Tendo como pano de fundo as datas comemorativas, em especial a "Semana da Consciência Negra", os eventos desenvolvidos pelo projeto pretenderam evidenciar personagens, bem como valorizar e acolher práticas culturais de matriz afro-brasileira.

* Palestras e debates: Ministradas por professores/as engajados nas temáticas do projeto ou por militantes de causas sociais. O intento seria incitar discussões e trocas de conhecimentos. As atividades foram abertas para o público externo. 
A promoção dos direitos humanos em uma instituição de ensino superior: relato de experiência do Projeto Diversidade

*Cine Diversidade: Direitos Humanos entre práticas e discursos: Mini "sala de cinema" onde foram transmitidos curtas-metragens que traziam em seu enredo uma narrativa que servissem de tópico para fomentar discussões sobre as temáticas da proposta.

\section{ATIVIDADES QUE FORAM DESENVOLVIDAS}

Antes de começar a aplicar as intervenções do Projeto Diversidade, a proposta passou pela aprovação da Pró Reitoria de Extensão e Assuntos Comunitários. Nesse trâmite foram definidas as ações que poderiam ou não ser acolhidas pela Instituição. Assim sendo, nessas reuniões foi estabelecido que as oficinas de cultura e os grupos de discussão eram proposições inviáveis, pois precisariam do acompanhamento de um/a professor/a da Instituição, além de demandar alocação de espaço físico específico. As demais ações tiveram a chancela da Universidade.

Dentre as intervenções que foram realizadas, o "Cine Diversidade: Direitos Humanos entre práticas e discursos", foi o evento de maior constância e, portanto, uma atividade que conferiu visibilidade ao projeto na Instituição, atribuindo-lhe uma identidade enquanto proposta destinada a representação positiva de minorias sociais e promoção dos direitos humanos e da cidadania.

O Cine Diversidade teve início em Abril de 2015 e era realizado inicialmente das $19 \mathrm{~h}$ às 19h30min com exibições quinzenais durante todo o primeiro semestre. A partir de agosto de 2015, as sessões passaram a ser mensais, no entanto, o tempo de intervenção foi ampliado para uma hora (18h30min às 19h30min). A atividade ocorria no Salão de Atos da Universidade.

Nesses eventos foram exibidos curtas-metragens que narravam práticas discriminatórias gestadas a partir da diversidade étnico-racial, de gênero e orientação sexual. Depois das exibições eram fomentados debates e discussões sobre as temáticas.

A divulgação dos curtas temáticos foi feita por meio do envio de e-mail aos/as acadêmicos/as da Instituição e também, via rede social (facebook). Nas artes dos eventos era comunicada a programação, a data, o horário, o local, o curta-metragem que seria exibido e o assunto a ser debatido na ocasião, facilitando o processo de identificação do/a acadêmico/a com a temática. Para além de sua divulgação via rede social e e-mail para os/as acadêmicos/as da Instituição e para a comunidade acadêmica, as atividades desenvolvidas no Cine Diversidade também foram noticiadas no Jornal NH (jornal da cidade de Novo Hamburgo - RS) sob o título: "CineDCE recomeça nessa quinta" e no Jornal Correio do Povo (jornal de Porto Alegre - RS) sob os seguintes dizeres: "Curtas temáticos”. 
A promoção dos direitos humanos em uma instituição de ensino superior: relato de experiência do Projeto Diversidade

A exibição de cada curta-metragem era seguida por uma fala do proponente do projeto. As falas tiveram como solo teórico as proposições dos Estudos Culturais. Mais especificamente, o conceito de representação foi utilizado como ferramenta de análise das questões emergentes dos curtas. Como forma de registro dos eventos, foram utilizados diários de campo para compilar as questões pontuadas pelos/as participantes e, sobretudo, compreender os significados dados por eles/as às temáticas de cada exibição e ao projeto, de modo mais amplo.

Pensados como forma de representação positiva de negros/as, mulheres e homossexuais, as exibições temáticas promovidas pelo Cine Diversidade pretenderam tensionar justamente os modos negativos como comumente esses grupos são representados nos espaços midiáticos e nas interações sociais, de modo geral. Nesse sentido, pretendeu-se evidenciar aos/às participantes o quanto essas representações se tornaram "naturais" (SILVA, 2001; 2014) e por essa razão, dificilmente percebidas como questões a serem questionadas e contextualizadas.

Dessa forma, foi demonstrado e reiterado durante todas as exibições do Cine Diversidade, a forma arbitrária como essas representações naturalizadas produziam significados e identidades negativas (SILVA, 2001; 2014) de negros/as, mulheres e homossexuais. Representações que contribuíam para a manutenção de uma cultura de preconceito, discriminação e intolerância às diferenças, impensada para um Estado democrático de direito.

Nesse sentido, as sessões temáticas oportunizaram aos/às acadêmicos/as da Instituição espaços para uma reflexão crítica sobre as temáticas privilegiadas pelo projeto. Pretendia-se sensibilizá-los/as e instigá-los/as a trabalhar com essas temáticas em outros espaços sociais/educacionais como multiplicadores/as de um discurso que advoga em favor da diversidade social e cultural.

No que se refere à aderência dos/as acadêmicos/as às programações do Cine Diversidade, foi possível perceber um público modesto de discentes presentes nas exibições, oscilando sempre entre 5 a 15 pessoas por evento. Pensando nisso, ao final de cada intervenção os/as acadêmicos/as eram questionados sobre os possíveis motivos dessa baixa adesão e as questões pontuadas por eles/as eram registradas em diário de campo.

Considerando as questões apresentadas pelos/as acadêmicos/as, foi possível observar três grandes razões para a baixa presença de pessoas aos eventos. Primeiro, devido às temáticas propostas pelo Cine Diversidade, que segundo eles/as, tratavam de pautas das quais as pessoas não querem discutir por serem polêmicas ou então, por serem consideradas uma "bobagem". Em segundo lugar devido aos horários de exibição dos curtas, pois segundo os/as acadêmicos/as, a maioria dos/as estudantes dependia de vans para se deslocarem até a Instituição e as vans 
A promoção dos direitos humanos em uma instituição de ensino superior: relato de experiência do Projeto Diversidade

chegavam poucos minutos antes do inicio das aulas (19h30min). Por fim, os/as acadêmicos/as atribuíram à divulgação insuficiente, já que a maioria deles/as havia sido informados/as da exibição dos curtas por meio de alguém ou quando passavam em frente ao Salão de Atos e percebiam a movimentação.

Mesmo sendo um número pequeno de participantes nos eventos, merece destaque o fato de que diversos/as acadêmicos/as atribuíram sua presença nas sessões ao seu reconhecimento como parte dos grupos minoritários representados pelo projeto. Justamente em meio a esses processos de identificação que o Cine Diversidade recebeu críticas em uma de suas exibições.

$\mathrm{Na}$ ocasião da exibição de um curta-metragem sobre violência doméstica, uma acadêmica ao término da transmissão, prontamente levantou-se e disse: "Não tinha nenhuma mulher no DCE que pudesse exibir esse curta? Estamos cansadas de ver vocês falarem por nós?”.

A intervenção da acadêmica fomentou um longo debate, não somente entre ela e o proponente do projeto, mas entre todas as pessoas presentes. A questão levantada por ela demonstra a importância do protagonismo das minorias no que se refere à ressignificação das relações sociais nas quais elas próprias são afetadas pelas inúmeras relações de poder.

A importância da questão levantada pela acadêmica fica evidente quando se observa que foi mediante o olhar masculino que em distintos momentos históricos foram construídas representações sobre as mulheres. Essas representações produziram significados que ao longo dos tempos vem legitimando normas de conduta, desigualdades e arbitrariedades impostas pelos homens sobre elas. Assim sendo, reivindicar o empoderamento dos espaços de representação possibilita as mulheres a participação efetiva na ressignificação das relações sociais e de sua autonomia (TEDESCHI, 2008; KLEBA, WENDAUSEN, 2009).

Por fim, acredita-se que a divulgação do Cine Diversidade por meio dos jornais " $\mathrm{NH"} \mathrm{e}$ "Correio do Povo", ainda que não tenha contribuído para o aumento do número de participantes do evento, demonstrou a repercussão do Projeto Diversidade para além da Instituição, demonstrando que as práticas desenvolvidas pelo projeto tinham "pernas" para alcançar contextos mais amplos. Cabe ressaltar que a ampliação das intervenções de $30 \mathrm{~min}$ para $1 \mathrm{~h}$ se deu por vias da própria Instituição, sinalizando acolhida ao debate e apoio ao projeto e com isso, permitiu momentos mais densos de discussão sobre as temáticas dos curtas.

As palestras também foram eventos muito importantes, na medida em que se trataram de espaços de trocas de conhecimentos e saberes nos quais contou-se com a participação de um número maior de acadêmicos/as ou de sujeitos interessados/as com as temáticas do projeto. 
A promoção dos direitos humanos em uma instituição de ensino superior: relato de experiência do Projeto Diversidade

Essas atividades ocorreram no Salão de Atos da Instituição e tiveram inicio as $19 \mathrm{~h} 30 \mathrm{~min}$ com término as $22 \mathrm{~h}$.

As palestras foram divulgadas por e-mail, rede social e via cartazes que foram expostos nos Campi da Instituição. A finalidade dessas intervenções foi coadunar um número mais expressivo de pessoas em torno das temáticas potencializadas pelo Projeto Diversidade.

No dia 12 de Maio de 2015, o Projeto Diversidade em parceria com o Diretório Acadêmico de Educação Física da Universidade, promoveu a palestra "Relações de Gênero nas práticas corporais". Esse evento lotou o Salão de Atos da Instituição e aproximou os/as acadêmicos/as das questões referentes aos estereótipos de gênero evidenciados nas práticas esportivas que incitam relações desiguais entre os sexos durante as atividades. A intenção era demonstrar que as representações de gênero contribuíam para perpetuar a noção de que determinadas atividades são destinadas as mulheres enquanto outras tantas não são.

A palestra "Relações de Gênero nas práticas corporais" contou com um significativo número de acadêmicos/as do curso de Educação Física. $\mathrm{Na}$ ocasião, a responsável pela palestra foi uma doutoranda na Universidade Federal do Rio Grande do Sul - UFRGS, que desenvolve pesquisas na área de relações de gênero com enfoque nas práticas esportivas.

Mesmo tendo apresentado dados concretos e elementos conceituais suficientes para evidenciar que às mulheres são atribuídos papéis sociais que tornam a sua presença impensada em determinados esportes ou práticas que exigem do corpo força ou avigoramento, percebeu-se que alguns alunos presentes no evento tentaram desqualificar a fala da palestrante no momento em que lhe foram concedido o espaço de fala/perguntas.

Ao falar de gênero e das possibilidades de ingresso das mulheres em modalidades esportivas nas quais são comumente invisibilizadas, a reação dos acadêmicos foi a de justificar a ausência das mulheres em determinados esportes por serem frágeis ou então, porque a presença delas no futsal, por exemplo, as tornaria masculinizadas. Além, disso a possibilidade de tematizar gênero nas aulas de Educação Física foi refutada tanto pelas acadêmicas quanto pelos acadêmicos, com algumas exceções.

No dia 22 de Setembro de 2015, ocorreu a palestra "Homofobia e os direitos LGBT", que pretendia proporcionar aos/as acadêmicos/as um espaço de questionamento e de reflexão sobre as relações sociais assimétricas que se forjam entre heterossexuais e homossexuais e, nesse sentido, apresentar as leis que visavam diretamente a promoção e a proteção dos direitos de lésbicas, gays, bissexuais e transgêneros. Esse evento contou com a presença de um número expressivo de acadêmicos e de acadêmicas de variados cursos. 
A promoção dos direitos humanos em uma instituição de ensino superior: relato de experiência do Projeto Diversidade

No dia 18 de Novembro de 2015, ocorreu a palestra "Cotas raciais nas Universidades", que teve como finalidade apresentar e discorrer sobre alguns pressupostos históricos, sociais e culturais relativos à implementação da política de cotas raciais nas Instituições de Ensino Superior.

Tal qual as atividades desenvolvidas no Cine Diversidade, as palestras também foram pensadas como forma de representação positiva das minorias sociais e as intervenções foram igualmente registradas via diário de campo. Dentre as palestras realizadas, a de cotas raciais foi a que teve o menor número de pessoas presentes, entre 25 a 30 pessoas. Apesar de ter ocorrido em horário de aula, os/as professores/as da Instituição não acompanharam, nem mesmo liberaram seus/as alunos/as para assisti-la.

Os eventos realizados em celebração à Semana da Consciência Negra foram realizados em dois momentos. Em Novembro de 2014, o Projeto Diversidade em parceria com o PIBID ${ }^{3}$ Educação Física e, também, com o D.A. de Educação Física da Instituição, promoveu atividades artísticas e culturais com o intuito de evidenciar personagens e acolher práticas de matriz afrobrasileira na Instituição. Na ocasião, em colaboração com os/as acadêmicos/as do PIBID, foi feita a exposição de banners que ilustravam figuras negras e suas contribuições para a história do país em âmbito político, econômico, artístico, social e cultural. As exposições tiveram inicio as $18 \mathrm{~h}$ e terminaram às $20 \mathrm{~h} 45 \mathrm{~min}$. Das $20 \mathrm{~h} 45 \mathrm{~min}$ às $21 \mathrm{~h} 15 \mathrm{~min}$, foi realizada uma grande Roda de Capoeira Inclusiva na área central da Instituição, contando com a presença de capoeiristas cadeirantes. Antecedendo a prática foi feita uma breve explanação sobre a emergência histórica da Capoeira e seus vínculos com a resistência negra à escravidão. A Instituição concedeu a liberação de todos/as os/as acadêmicos/as para acompanhar ou mesmo, vivenciar, a Roda de Capoeira proposta pelo projeto em articulação com o DA de Educação Física da Universidade.

Em Novembro de 2015, o Projeto Diversidade em nova aproximação com o DA de Educação Física da Universidade, elaborou duas intervenções concomitantes durante o intervalo estendido. $\mathrm{Na}$ área central da Instituição, foi realizada uma nova Roda de Capoeira, enquanto na rua coberta, foi realizado um Flas $\mathrm{Mob}^{4}$ com coreografias e músicas de origem afro-brasileira, com intuito de valorizar a contribuição negra na arte e na cultura corporal.

Esses eventos em celebração a Semana da Consciência Negra suscitaram críticas. Apesar do número expressivo de participantes nas ocasiões e da repercussão positiva dos eventos na

\footnotetext{
3 Programa Institucional de Bolsa de Iniciação à Docência.

$4 \quad$ Flas Mob é uma apresentação ensaiada previamente por um grupo de pessoas. No entanto, o diferencial dessas exibições está no fato de que elas ocorrem em ambientes informais de forma repentina e inesperada pelas pessoas presentes no local.
} 
A promoção dos direitos humanos em uma instituição de ensino superior: relato de experiência do Projeto Diversidade

Instituição, alguns/as acadêmicos/as de Educação Física questionaram a necessidade de apoio do Diretório Acadêmico do curso às intervenções, pois segundo eles/as, o Dia da Consciência Negra não era prioridade do curso e que os esforços deveriam ser investidos em outras direções.

\section{CONSIDERAÇÕES FINAIS}

Tratar sobre preconceitos nas suas mais variadas expressões sempre será uma questão complexa, porém, necessária. Complexa porque o Projeto Diversidade pretendeu em certa medida, questionar um "modelo" eurocêntrico, masculino e heterossexual hegemônico, perpetuado no tempo e no espaço e reiterado a cada representação negativa daqueles/as sujeitos que são distanciados/as da "norma". Uma necessidade em razão das distintas formas de discriminação, opressão e violência física e psicológica vivenciadas por negros/as, mulheres e homossexuais ao longo dos tempos.

O Projeto Diversidade foi uma proposta de intervenção política, educacional e social que foi desenvolvida pela Secretaria de Direitos Humanos do Diretório Central dos Estudantes. Essa proposta de promoção dos direitos humanos e da cidadania foi pensada e destinada às minorias sociais, pretendendo conceder voz, visibilidade, reconhecimento e valorização a essas coletividades.

Nesse sentido, as atividades desenvolvidas pelo projeto foram pensadas como representações positivas dessas minorias, como forma de positivar identidades que historicamente foram postas às margens da centralidade em que se localiza homens, brancos e heterossexuais.

No entanto, cabe mencionar que em alguns momentos as atividades foram alvos de críticas por parte de alguns/as acadêmicos/as da Instituição. As críticas vindas da acadêmica durante o curta-metragem sobre violência doméstica demonstra a importância política de se considerar o protagonismo desses grupos nos espaços de representação, de visibilidade e de fala. Ainda que a proposta tivesse a intenção de contribuir para a problematização das relações étnicoraciais, de gênero e de orientação sexual, considera-se que o projeto tenha falhado neste sentido, por não ter considerado o protagonismo dos distintos grupos no momento de mediação das intervenções.

Além disso, ao pensar na resistência dos acadêmicos à presença das mulheres em algumas práticas esportivas, manifesta na ocasião da palestra sobre relações de gênero e, ainda, tendo em vista a reivindicação de protagonismo feminino vivenciada durante a realização do Cine, 
A promoção dos direitos humanos em uma instituição de ensino superior: relato de experiência do Projeto Diversidade

considera-se que faltou um pouco de sensibilidade em perceber que as questões femininas mereciam maiores atenções por serem temáticas suscitadas pelos/as próprios/as acadêmicos/as. Além disto, poderiam ter sido realizadas intervenções que proporcionassem espaços de fala para as acadêmicas da Instituição identificadas com os debates sobre relações de gênero e feminismo.

Ademais, os eventos que colocavam em questão a presença de negros e negras nas Universidades, bem como a valorização da cultura negra, também poderiam ter sido mais explorados tendo em vista a baixa adesão acadêmica e os discursos que desqualificavam os eventos em celebração da Semana da Consciência Negra.

De qualquer forma, considerando a complexidade das temáticas propostas pelo projeto pode-se dizer que essas resistências eram esperadas, por serem questões que envolvem uma série de tabus, controversas e polêmicas.

Também é sintomático pensar que muitos/as dos/as acadêmicos/as que compareceram aos eventos disseram que se reconheciam como minorias sociais representadas pelo Projeto Diversidade. Assim sendo, considerando a complexidade dos processos de identificação e a contingência das identidades na pós-modernidade (SILVA, 2001; 2014) supõe-se que as intervenções do projeto tenham oferecido em algum momento e em certa medida, significados positivos para a afirmação de suas identidades (étnica, de gênero ou sexual).

Como contribuições do projeto às temáticas privilegiadas, considera-se o incentivo a uma cultura de debate e de reflexão política sobre as questões raciais, de gênero e de diversidade sexual vinculadas à promoção dos direitos humanos e da cidadania.

Em suma, o Projeto Diversidade representou um exercício de cidadania e humanismo na Instituição, pretendendo de algum modo oferecer aos/às acadêmicos/as, recursos que cooperassem para produção de práticas pedagógicas destinadas à promoção da igualdade social, da cidadania e dos direitos humanos a partir da desconstrução de representações negativas de minorias sociais. Para tanto, foram realizadas intervenções que desempenharam o papel de bem representar os/as negros/as, as mulheres e os/as homossexuais, incitando a produção de uma cultura de respeito e valorização da diferença na e pela Instituição.

\section{REFERÊNCIAS}

BRASIL. Conselho Nacional de Combate à Discriminação. Programa de combate à violência e à discriminação contra GLTB e promoção da cidadania homossexual. Brasília : Ministério da Saúde, 2004. 
A promoção dos direitos humanos em uma instituição de ensino superior: relato de experiência do Projeto Diversidade

BRASIL. Constituição (1988). Constituição da República Federativa do Brasil. Brasília,DF,Senado. Disponível

em: http://www.planalto.gov.br/ccivil_03/constituicao/constituicao.htm. Acesso em 29 de Maio de 2014.

BRASIL. Lei 10. 639, de 9 de Janeiro de 2003. Diário Oficial da União. Brasília, DF, 2003.

BRASIL. Ministério das Relações Exteriores. Nota n. 197 de 07/06/2013. OEA aprova a Convenção Interamericana contra o Racismo, a Discriminação Racial e Formas Correlatas de Intolerância e a Convenção Interamericana contra toda Forma de Discriminação e Intolerância. Disponível em:http://www.itamaraty.gov.br/. Acesso em: 29 de Maio de 2014.

BRASIL. Presidência da República. Secretaria de Políticas para as Mulheres. Plano Nacional de Políticas para as Mulheres. Brasília: Secretaria de Políticas para as Mulheres, 2013.

BRASIL. Resolução nº 1, de 17 de Junho de 2004. Diário Oficial da União. Brasília, DF, 2004.

BRASIL. Secretaria de Educação Continuada, Alfabetização e Diversidade (Secad/MEC), Brasília, DF, 2007.

CANDAU, Vera Maria. Direitos humanos, educação e interculturalidade: as tensões entre igualdade e diferença. Revista Brasileira de Educação, v. 13, n. 37, p. 45-56, 2008.

CANDAU, Vera Maria. Diferenças culturais, interculturalidade e educação em direitos humanos. Educação \& Sociedade, v. 33, n. 118, p. 235-250, 2012.

GOES, Fernanda Lira; SILVA, Tatiana Dias. O regime internacional de combate ao racismo e à discriminação racial. Texto para discussão, Instituto de Pesquisa Econômica Aplicada (IPEA) n ${ }^{\circ}$ 1882. Rio de Janeiro, 2013.

HALL, Stuart. A centralidade da cultura: notas sobre as revoluções culturais do nosso tempo. Educação \& realidade, v. 22, n. 2, p. 15-46, 1997. 
A promoção dos direitos humanos em uma instituição de ensino superior: relato de experiência do Projeto Diversidade

KLEBA, Maria Elisabeth, WENDAUSEN, Agueda. Empoderamento: processo de fortalecimento dos sujeitos nos espaços de participação social e democratização política. Revista Saúde e sociedade, v. 18, n. 4, p. 733-743, 2009.

PIOVESAN, Flávia et al. Ações afirmativas da perspectiva dos direitos humanos. Cadernos de Pesquisa, v. 35, n. 124, p. 43-55, 2005.

SILVA, Tomaz Tadeu da. A produção social da identidade e da diferença. In: Identidade e diferença: a perspectiva dos Estudos Culturais. Petrópolis: Vozes, 2014. p. 73- 102.

SILVA, Tomaz Tadeu da. Documentos de identidade: uma introdução às teorias do currículo. 3. ed. Belo Horizonte, MG: Autêntica, 2011.

SILVA, Tomaz Tadeu da. O currículo como fetiche: a poética e a política do texto curricular. 2. ed. Belo Horizonte, MG: Autêntica, 2001.

TEDESCHI, Losandro Antonio. História das mulheres e as representações do feminino. Campinas: Curt Nimuendajú, 2008, 144 p.

WOODWARD, K. Identidade e diferença: uma introdução teórica conceitual. In: SILVA, T. S. (org.) Identidade e diferença: a perspectiva dos Estudos Culturais. Petrópolis: Vozes, 2014. p. 7 72.

WORTMANN, Maria Lúcia Castagna. O uso do termo representação na educação em Ciências e nos Estudos Culturais. Pro Posições, Campinas, v. 12, n. 1, p. 151-61, 2001. 